\title{
Difficult airway management: burning no bridges
}

\author{
Sara Aloqab ${ }^{1^{*}}$, Mahesh Chandrashekhariah ${ }^{2}$, Vishal Shah ${ }^{2}$, Shahid Adeel ${ }^{3}$ \\ Senior House Officer ${ }^{I}$, Senior Registrar ${ }^{2}$, Consultant ${ }^{3}$, Department of Anaesthesia and Pain Management, \\ King Hamad University Hospital, Bahrain
}

\begin{abstract}
Ameloblastoma is a benign tumor that arises from odontogenic epithelium. It may present a challenge to anaesthetists as it can distort the facial contours and can make bag-mask ventilation difficult. We present a first case of ameloblastoma in our hospital where a 38year-old female was scheduled for a right mandibulectomy and reconstruction of the mandible with a custom-made titanium implant. Awake fiberoptic intubation was planned as a first choice for induction of anaesthesia as any other technique may have led to serious airway complications. We believe that airway management in difficult airway cases should always be based on the principle of "burning no bridges".
\end{abstract}

Keywords: Ameloblastoma; fiberoptic intubation; difficult airway; mandibular mass

\section{Introduction}

Ameloblastoma is a benign intermittent growing tumor that affects the mandible more than the maxilla and occurs especially in the molar-ramus area (Figure 1).It is normally nonfunctional and unicentric. Ameloblastoma may present a challenge to anesthetists as it has the capacity to cause severe disfigurement and alter the airway anatomy which may reflect directly on the ease of ventilation and intubation. The tumor may also be associated with trismus and intraoral extension which can cause airway obstruction and further difficulty in visualizing the glottis. ${ }^{1}$

\section{Case Report}

We present a case of a 38-year-old female patient with a huge swelling over the right lower maxilla and mandible. (Figure 2) The histological diagnosis was of benign ameloblastoma.

*Correspondence: Sara Aloqab

E mail: staloqab@gmail.com

https://orcid.org/0000-0001-9297-6534

Received: 27/05/2019

Accepted: 30/05/2019

DOI: http://doi.org/10.4038/slja.v27i2.8458

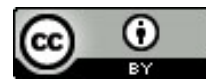

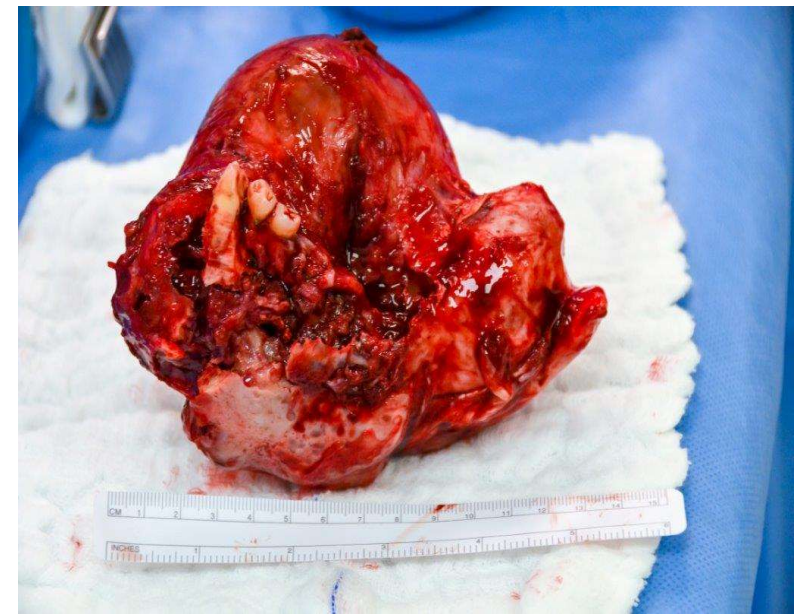

Figure 1

She was scheduled for a right mandibulectomy and re-construction using a custom-made titanium implant. She had a past medical history of hypertension and was compliant with her antihypertensive treatment.

On airway examination, she had a large swelling on the right side of the face with adequate mouth opening and was classified as Mallampati grade 2. She had no history of stridor or hoarseness. CT scan of the oropharynx and neck was reviewed, and it was noticed that there was no involvement of the larynx and trachea. 


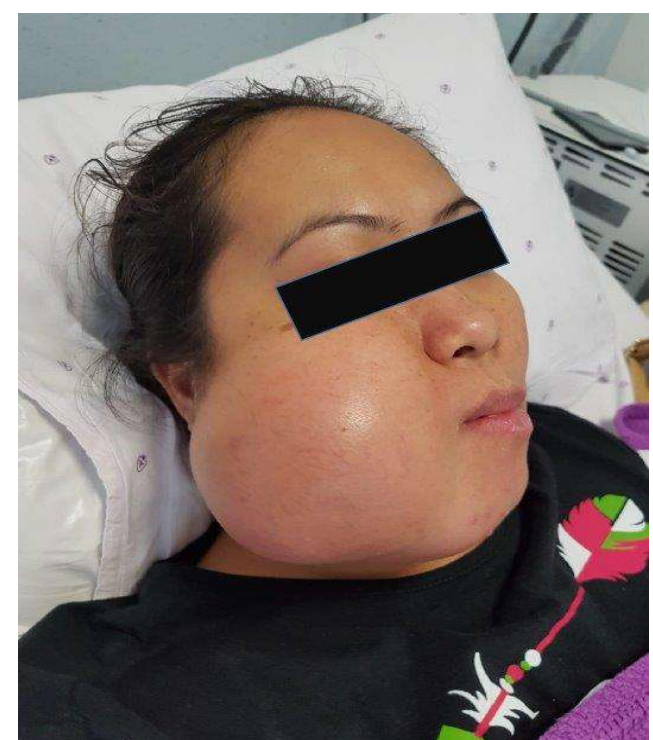

\section{Figure 2}

When considering any patient for general anaesthesia, effective planning should involve bag mask ventilation followed by laryngoscopy and tracheal intubation. This patient posed a significant risk of failed bag-mask ventilation because of the enormous mass around her lower jaw. Our concern was that in case of any difficulty during bag-mask ventilation, jaw thrust and chin lift maneuvers would be impossible to perform and that would leave her at significant risk of serious hypoxia and death.

The most sensible approach was to proceed with awake fiberoptic intubation without compromising her respiratory drive. Awake fiberoptic intubation is also helpful in recognizing any potential difficulty caused by distortion secondary to the tumor.

In this patient, other options for induction of general anaesthesia could have included awake video-laryngoscopy, and laryngoscopy following an inhalational induction of anaesthesia with slightly more risks in comparison to awake fiberoptic intubation. All these options were discussed with the patient and she consented to have an awake nasal fiberoptic intubation. (Figure 3)

On the day of surgery, patient was pre-medicated with glycopyrrolate $0.2 \mathrm{mg}$ intravenously to reduce oral secretions but no sedation was used throughout the fiberoptic intubation as we did not want to take any risk of a compromised airway.

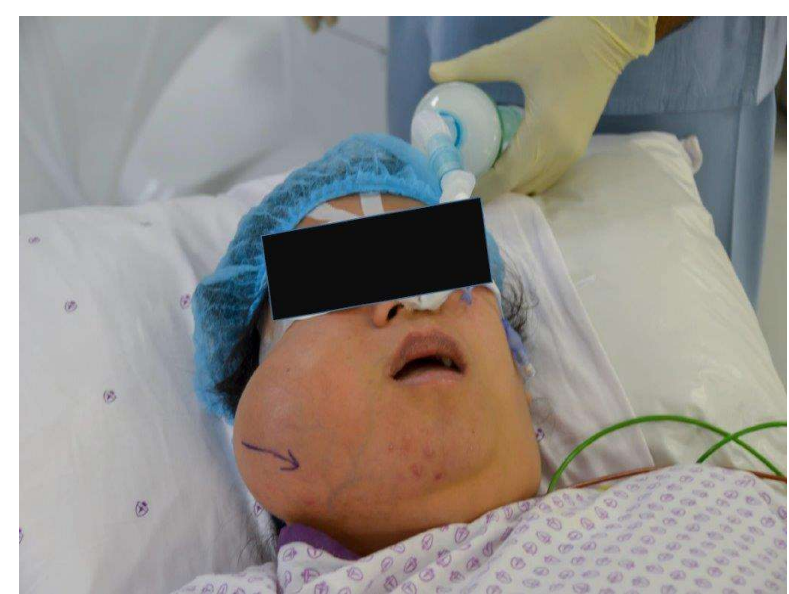

Figure 3

After lubrication of the left nasal passage, a flexible bronchoscope was inserted and a nasal RAE endotracheal tube (size $6.5 \mathrm{~mm}$ ) was passed over the bronchoscope through the left nasal passage. After identification of all anatomical structures with the bronchoscope, endotracheal intubation was successfully carried out under direct visualization. Operative surgical time was about 6 hours. Postoperatively the patient was transferred to the intensive care unit and was extubated next day.

\section{Discussion}

Ameloblastoma accounts for $1 \%$ of all oral tumors and about $9-11 \%$ of odontogenic tumors. ${ }^{2}$ The aetiology is unknown. It is usually asymptomatic and discovered incidentally on routine radiographs, but it can present with jaw expansion which may lead to root resorption and tooth displacement. ${ }^{3}$ It appears on x-ray as a lytic lesion with scalloped margins. ${ }^{4}$ Treatment can be either conservative or radical depending on the clinical type, however, surgery is considered the elective treatment of ameloblastoma. $^{5}$

Head and neck pathologies can be challenging due to their anatomical position near the airway which may be distorted by their presence. A study published by Cook et al showed that head and neck pathology is present in approximately $39 \%$ of cases in which major complications of airway management occurred and $75 \%$ of "cannot intubate, cannot ventilate" situations where an emergency surgical airway was required. ${ }^{6,7}$ 
Awake fiberoptic intubation remains the accepted standard in elective airway management of those patients where difficult airway is anticipated. ${ }^{8}$ By using this technique, intubation can be performed prior to the induction of general anaesthesia which reduces the risks of failed intubation, airway collapse, inadequate ventilation / oxygenation as well as "cannot intubate/cannot ventilate" scenario. ${ }^{8}$ However, adequate time for preparation and patient cooperation are both required for the success of this technique. ${ }^{8}$

In massive ameloblastoma such as in our case, keeping the patient awake during fiberoptic intubation permits easy visualization of the upper airway, intact muscles tone and hence preserving the anatomy of the airway. ${ }^{9}$ It also preserves the patient's ability to spontaneously breath.

Awake fiberoptic intubation can be done using oral or nasal routes. The oral route is used in the majority of cases. The nasal route may be indicated in cases with severe mouth opening limitation, strong gag reflex, or if the surgical procedure requires nasotracheal intubation. In our case we intubated through the nose as the surgical team wanted to have optimal access to the oral cavity. The risks of nasal intubation include epistaxis, trauma to the nasal turbinates, and submucosal tunneling in the nasopharynx. ${ }^{8}$

Sedation is often required during awake intubation to improve patient tolerance by reducing anxiety and providing analgesia and amnesia. ${ }^{10}$ The decision to use sedation is made on a case-by-case basis and sedative agents should be carefully titrated to maintain adequate respiration, airway reflexes, and consciousness. ${ }^{8}$

\section{Conclusion}

Airway management in difficult airway cases should always be based on the principle of "burning no bridges". As in this case, awake fiberoptic intubation should be the first choice and anaesthetists should have a very low threshold for opting for this technique particularly in the case of masses in and around the airway.

\section{References}

1. Sahoom T, Ambardekar, M, Patel, R Anaesthetic management in a case of Ameloblastoma with free
Fibular graft. The Internet Journal of Anesthesiology. 2007; 17: (1)

https://doi.org/10.5580/735

2. Nakamura N, Mitsuyasu T, Higuchi Y, Sandra F, Ohishi M. Growth characteristics of ameloblastoma involving the inferior alveolar nerve: A clinical and histopathologic study. Oral Surg Oral Med Oral Pathol Oral RadiolEndod. 2001;91:557-62 https://doi.org/10.1067/moe.2001.113110 PMid:11346735

3. Hariam, Shadab M, Laxman R, Ameloblastoma of Anterior Mandible, J Maxillofac Surg. 2014; 5(1): 47-50 https://doi.org/10.4103/0975-5950.140173 PMid:25298718 PMCid:PMC4178356

4. Underhill TE, Katz JO, Pope TL Jr, Dunlap CL. Radiologic findings of diseases involving the maxilla and mandible. AJR Am J Roentgenol 1992; 159(2):345-350

https://doi.org/10.2214/ajr.159.2.1632353

PMid:1632353

5. Neagu D, Escuder-de la Torre O, Vázquez-Mahía I. Surgical management of ameloblastoma. Review of literature, J Clin Exp Dent. 2019;11(1):e70-5.

https://doi.org/10.4317/jced.55452

PMid:30697397 PMCid:PMC6343988

6. Cook T, woodall N, Frerk C, Major complications of airway management in the UK: results of the Fourth National Audit Project of the Royal College of Anaesthetists and the Difficult Airway Society. Part 1. Br J Anaesth. 2011;106 (5): 617-631 https://doi.org/10.1093/bja/aer058

PMid:21447488

7. Frerk C, Cook T. Management of the "can't intubate can't ventilate" situation and the emergency surgical airway. In: 4th National Audit Project of the Royal College of Anaesthetists: Major complications of airway management in the UK, Patel A, Pearce A, Pracy P (Eds) p.143, The Royal College of Anaesthetists and the Difficult Airway Society, 2011. p.105.

8. Hagberg C, Artime C, Flexible scope intubation for anesthesia, www.uptodate.com, 2018

9. Batra U, Usha G, Gogia Anesthetic management of schwannoma of the base of the tongue, J Anaesthesiol Clin Pharmacol. 2011;27(2): 241-243. https://doi.org/10.4103/0970-9185.81830

PMid:21772689 PMCid:PMC3127308

10. Leslie D, Stacey M, Awake intubation Continuing Education in Anaesthesia Critical Care \& Pain, 2015; 15(2) :64-67 https://doi.org/10.1093/bjaceaccp/mku015 